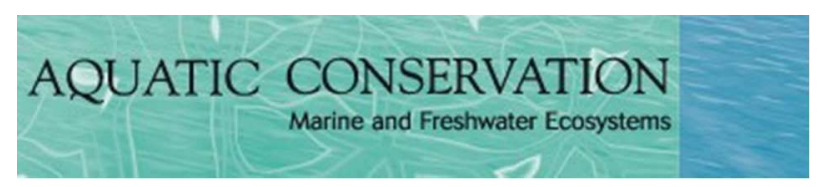

\title{
Modelling functional fish habitat connectivity in rivers. A case study for prioritizing restoration actions targeting brown trout
}

\begin{tabular}{|c|c|}
\hline Journal: & Aquatic Conservation: Marine and Freshwater Ecosystems \\
\hline Manuscript ID & AQC-16-0164.R2 \\
\hline Wiley - Manuscript type: & Research Article \\
\hline Date Submitted by the Author: & $\mathrm{n} / \mathrm{a}$ \\
\hline Complete List of Authors: & $\begin{array}{l}\text { Roy, Mathieu; INRS Eau Terre et Environnement, } \\
\text { Le Pichon, Céline; Irstea }\end{array}$ \\
\hline $\begin{array}{l}\text { Broad habitat type } \\
\text { (mandatory) select 1-2: }\end{array}$ & river $<$ Broad habitat type, stream $<$ Broad habitat type \\
\hline $\begin{array}{l}\text { General theme or application } \\
\text { (mandatory) select 1-2: }\end{array}$ & $\begin{array}{l}\text { habitat management }<\text { General theme or application, habitat mapping }< \\
\text { General theme or application }\end{array}$ \\
\hline $\begin{array}{r}\text { Broad taxonomic group or } \\
\text { category (mandatory, if } \\
\text { relevant to paper) select } 1-2 \text { : }\end{array}$ & fish $<$ Broad taxonomic group or category \\
\hline $\begin{array}{l}\text { Impact category (mandatory, } \\
\text { if relevant to paper) select 1- } \\
2:\end{array}$ & \\
\hline
\end{tabular}


1 Modelling functional fish habitat connectivity in rivers: A case study for prioritizing

2 restoration actions targeting brown trout

3

4 Mathieu L. Roy ${ }^{1-2}$ and Céline Le Pichon ${ }^{1}$

5

$6 \quad{ }^{1}$ IRSTEA, Hydro-Ecology, Antony, France

$7 \quad{ }^{2}$ Institut national de la recherche scientifique, Centre Eau Terre Environnement, Quebec

8 City, Qc, Canada

10 Abstract

11 1. Throughout the world, decreased connectivity of fluvial habitats caused by

12 anthropogenic river channel alterations such as culverts, weirs and dykes is pointed out as

13 an important threat to the long term survival of many aquatic species. In addition to

14 assessing habitat quality and abundance, wildlife managers are becoming increasingly

15 aware of the importance of taking into account habitat connectivity when prioritizing

16 restoration efforts. In this paper, a new approach of spatial analysis adapted to rivers and

17 streams is proposed to model 2D functional habitat connectivity, integrating distance,

18 costs and risk of travelling between habitat patches (e.g.. daily-use, spawning, refuge) for

19 particular fish species, size classes and life stages.

202 . This approach was applied to a case study in which brown trout (Salmo trutta)

21 habitat accessibility was examined and compared under various scenarios of stream

22 restoration in a highly fragmented stream in Ile-de-France. Probabilities of reaching 
23 spawning habitats were estimated from a trout-populated area located downstream of the

24 barriers and from potential daily-use habitat patches across the stream segment.

25 3. The approach successfully helped prioritize restoration actions by identifying 26 options which yield a maximal increase in accessible spawning habitat areas and 27 connectivity between spawning habitat and daily-use habitat patches. This case study 28 illustrates the practical use of the approach and the software in the context of river habitat 29 management.

30 Keywords: river, stream, habitat management, habitat mapping, fish.

31 Correspondance to : Mathieu Roy, Institut national de la recherche scientifique, Centre 32 Eau Terre Environnement, 490 rue de la Couronne, Quebec City, Québec, G1K9A9, 33 Canada. E-mail : mathieu.roy@ete.inrs.ca 


\section{Introduction}

36 To survive, grow and complete their life cycle, many fish species need to chronologically

37 access different habitats providing for particular life functions (i.e. feeding, refuge, 38 spawning) and life stages. In rivers and streams, the spatial and temporal variation of

39 flow velocity, bed morphology, vegetation and temperature contribute to creating and

40 maintaining a dynamic mosaic of habitat patches (Statzner, 1981, Pringle et al., 1988).

41 The resulting heterogeneity provides a variety of complementary functional habitats for

42 fish (Schlosser, 1995, Le Pichon et al., 2016). The spatial configuration of

43 complementary habitats and the connectivity between them affects fish dispersion and

44 migration, which in turn have an impact on the spatial variation in genetic diversity, 45 community composition and metapopulation dynamics (Fullerton et al., 2010).

46 Throughout the world, anthropogenic river channel alterations such as dams, culverts,

47 weirs, dykes and derivations have over the years decreased the natural connectivity of

48 fluvial systems, restricting the movement of organisms and threatening biodiversity

49 (Elosegi et al., 2010). To tackle this issue, aquatic conservation and management

50 planners are putting increasing effort in stream restoration aiming at reducing habitat 51 fragmentation (Merenlender and Matella, 2013).

53 Habitat connectivity describes how the environment facilitates or restricts dispersal or 54 migration of organisms between habitats patches (Taylor et al., 1993). The so-called 55 'structural' habitat connectivity reflects the physical structure of the landscape (i.e. shape, 56 size and relative location of habitat patches, presence of natural and artificial barriers) 
57 (Baudry and Merriam, 1988). In contrast, 'functional' connectivity reflects how

58 organisms respond to the physical structure of the river in terms of mobility between

59 habitats. Being species- and life stage- specific, functional connectivity in riverscapes

60 defines the capacity or the ease at which aquatic organisms can travel from a habitat

61 patch to another depending on their swimming capacities or dispersal behaviour, energy

62 costs and mortality risks involved. Considering its importance for the persistence of

63 populations (Fahrig and Merriam, 1994), gaining knowledge of species-specific

64 functional connectivity for particular rivers is crucial, and provides in many cases a more

65 useful perspective for addressing specific management problems. In particular, assessing

66 functional connectivity might be especially valuable in the context of barrier removal

67 projects, as it could help decision makers to prioritize restoration actions (Branco et al.,

68 2014, Rivers-Moore et al., 2016).

70 Estimates of functional habitat connectivity can be obtained through empirical

71 measurements of fish dispersion and migration rates using various bio-telemetry and

72 mark-and-recapture techniques (Kanno et al., 2014). At the scale of river networks,

73 population genetics can also be used to determine biological connectivity through its

74 footprints in the reproductive history of individuals and populations (Torterotot et al.,

75 2014). However, acquiring such data is costly and can be logistically challenging. An

76 alternative solution is to model functional habitat connectivity, providing quantitative

77 estimates of accessible habitat area. This approach might be particularly useful as a

78 decision-support tool for wildlife managers and landscape planners. 
80 Terrestrial landscape ecologists have a tradition of modeling connectivity using

81 numerous approaches based on Euclidian distances (Mühlner et al., 2010), diffusion

82 (Reeves and Usher, 1989), corridor definition (Gilbert-Norton et al., 2010) and graph

83 theory (Rayfield et al., 2011). Although connectivity has been widely studied in streams

84 and rivers (e.g. Pringle, 2003, Moilanen et al., 2008), methodologies to model stream

85 habitat connectivity adapted to the longitudinal constraints of a river structure and the

86 directionality imposed by flow velocity are more recent (Fullerton et al., 2010). Among

87 different research paths, 1D methods based on graph- or network theory have recently

88 generated enthusiasm (Eros et al., 2011, Van Looy et al., 2014). While graph-theory is

89 useful for providing a schematic representation of the interconnections between habitat

90 patches at the scale of large river networks, it might not always be the best option to

91 characterize connectivity of smaller-scale continuous habitat maps, particularly to

92 account for areas located outside suitable habitat patches.

93 An alternative approach to modelling habitat connectivity is to estimate the shortest

94 distance (within wetted area) to or from habitat patches at the pixel level of 2D raster

95 maps (Jensen et al., 2006). As heterogeneous environments might induce variable

96 resistance to movement, cost-distance functions (Knaapen et al., 1992) can be used in

97 order to identify least-cost paths (or functional distances) between locations (Adriaensen

98 et al., 2003). This approach is well suited to analyze continuous aquatic data over large

99 extents, which are becoming increasingly available. In particularly, high resolution

100 remote sensing imagery provides solutions to map numerous variables such as

101 bathymetry and water temperature (McKean et al., 2009, Dugdale et al., 2013, Tamminga

102 et al., 2015). A 2D raster-based approach to analyze connectivity is particularly useful to 
103 describe large rivers, fluvial lakes and estuaries with connected waterbodies, where fish

104 can possibly move in every direction rather than only up- or downstream in a network.

105 Hence, by adopting a continuous view of the river and its spatially heterogeneous

106 environment, this approach is in line with a "riverscape perspective", which is

107 increasingly considered as desirable for carrying out effective research and planning 108 conservation (Fausch et al., 2002, Wiens, 2002, Fullerton et al., 2010, White et al., 109 2014).

110 The objective of this paper is to (i) describe a free software (Anaqualand 2.0) designed to

111 quantify functional habitat connectivity of mobile organisms in streams and rivers and to

112 (ii) show the usefulness of this approach to evaluate the potential connectivity changes

113 resulting from river modifications. Based on least-cost path modeling, Anaqualand 2.0

114 software differs from available GIS tools by accounting for fish movement directionality

115 (up- and downstream) and allows converting connectivity between habitat patches into

116 species- and life-stage-specific probability of access. To illustrate this potential,

117 Anaqualand 2.0 was used in a case study to model brown trout (Salmo trutta) habitat

118 connectivity and the probability of reaching spawning sites (ie. habitat accessibility)

119 under scenarios of barrier removal to help prioritize connectivity restoration actions.

\section{Anaqualand 2.0 program overview}

122 The software allows the user to quantify the structural and functional connectivity 123 between habitat patches or point coordinates in the upstream, downstream or in both 124 directions (Le Pichon et al., 2006). Structural connectivity can be quantified by 125 calculating instream distances between habitat patches (i.e. shortest path within the 
126 channel boundary) and resistance to movement is assumed to be homogeneous across the

127 river. In contrast, functional connectivity integrates the distance between patches and a

128 spatially variable resistance to movement allowing to identify least-cost paths between

129 patches expressed as a minimal cumulative resistance (MCR) (Knaapen et al., 1992,

130 Adriaensen et al., 2003). This approach is based on the general assumptions of optimal

131 foraging theory (Davies et al., 2012) predicting that fish will tend to minimize the energy

132 costs while they travel (Giske et al., 1998). Thus, the least-cost path between two

133 functional habitat patches might sometimes imply travelling a longer distance than the

134 shortest instream distance in order to avoid an obstacle or risky area. Anaqualand 2.0 is 135 freely available and can be downloaded from the internet 136 (http://www6.rennes.inra.fr/sad/Outils-Produits/Outils-informatiques/Anaqualand).

139 Anaqualand 2.0 requires to input a raster map (ascii format) describing the physical 140 template of the river. Coordinates of the upstream and downstream ends of the study 141 stream are required to indicate stream flow directionality. Depending on data availability 142 and objectives, it may be a simple binary map displaying the river outline (water/not 143 water) or a more detailed categorical map containing depth classes, morphological units, 144 physical or chemical barriers, etc. Multiple sets of resistance values, for up- and 145 downstream directions, specific to each species and life stage studied, can be uploaded. 146 One or several functional habitats maps can be added to examine the connectivity to or 147 between them (e.g. refuge to foraging habitat or spawning to nursery). Optimally, 148 resistance to movement can be determined through empirical studies of fish mobility in 
149 heterogeneous environments (see Beier et al., 2008 for review). However, as such studies

150 are complex to carry out, few empirical resistance estimates have been yet published (but

151 see Turgeon et al., 2010). Therefore, from a management perspective, resistance values

152 based on expert opinion and literature review (Beier et al., 2008) is often considered as a

153 justifiable trade-off.

154

155 Instream distances and functional distance maps

156 Instream distances are defined as the shortest paths between a source and a target within

157 the channel boundary. Functional distance, defined as the least-cost path between two

158 locations, is expressed as the minimal cumulative resistance (MCR). Anaqualand 2.0

159 allows the user to create functional distance maps, in which every pixel values express

160 the minimal cost to reach the closest habitat of the specified type. Functional distance can

161 be calculated: 1) either for all patches or for a selection of patches, 2) either for all

162 patches simultaneously (one map of functional distance to reach the nearest patch) or

163 separately for each patch (several maps of functional distance to reach single patches), 3)

164 either in upstream (functional distance to reach the nearest upstream patch), in

165 downstream (functional distance to reach the nearest downstream patch) or in both

166 directions (functional distance to reach the nearest patch independently of flow direction).

167 Probability of access maps

168 As accessibility decreases with functional distance traveled, functional distance maps

169 (MCR) can be converted into accessibility maps using a decreasing probability

170 transformation function and a mobility coefficient $(\alpha)$ (Le Pichon et al., 2006). Four

171 functions are available: 1) linear, 2) Gaussian, 3) exponential or 4) threshold-driven. The 
172 function used depends on the behaviour of the target species. In case of uncertainty,

173 multiple curves can be computed as a way to perform a sensitivity analysis. A Gaussian

174 transformation would illustrate a population characterized by most fish reaching

175 moderate distances and few traveling long distances; while an exponential transformation

176 would characterize a population in which few fish that are mobile may travel over longer

177 distances and a threshold driven curve could be used when resistance features present

178 lethal conditions or an absolute physical barriers. The mobility coefficient $(\alpha)$, a

179 parameter estimated in meters is calibrated based on the existing knowledge of the

180 species- and life-stage-specific home range extent or migration distances (Hanski, 1994,

181 Vos et al., 2001).

182

\section{Case study}

184 Context and objectives

185 With the adoption of the Water Framework Directive (Council of the European 186 Communities, 2000), European countries have referenced and mapped stream barriers 187 and have set targets of conservation and restoration of water bodies. In this context, the 188 Haute Vallée de Chevreuse Natural Regional Park, France, is carrying out a project 189 aiming at restoring ecological continuity of streams on its territory using barrier removal 190 or channel restoration at the bottom of the valley. However, due to the high number of 191 barriers and the limited resources, action prioritization is crucial to maximize their 192 potential short and medium term ecological benefits (Gangloff, 2013).

193 Brown trout (Salmo trutta) is a European species of salmonid that is considered as a 194 flagship species in France, indicator of good ecological status of rivers and important for 
195 sport fishing. In the Ile-de-France region, where streams are highly impacted by human

196 activities and populations have markedly declined, it remains of high conservation

197 importance in stream where small populations still exist. Allowing free passage might be

198 important for freshwater brown trout resident populations, as mature individuals tend to

199 migrate upstream in autumn from their daily-use rearing habitat to suitable spawning

200 grounds (Jonsson and Jonsson, 2011). Outside the spawning season, most individuals

201 display restricted mobility, while a fraction of the population is more mobile and move

202 between suitable daily-use habitat (Jonsson and Jonsson, 2011). Therefore, restoring free

203 passage outside the spawning season might allow fish to colonize upstream areas and

204 increasing stream productivity. The progressive colonization of daily-use habitats might

205 be stepping stones providing access to further spawning habitats. In this context,

206 Anaqualand 2.0 appears to be an ideal tool for quantifying the changes in habitat

207 availability associated with different scenarios of barrier removal in order to guide the

208 allocation of resources in restoration of the Mérantaise. Specifically, this case study aims

209 at estimating 1) accessibility to spawning/daily-use habitat from the downstream end of

210 the study area, providing benefits of connectivity restoration for the downstream

211 population, and 2) accessibility to spawning habitats from any daily-use habitat patches,

212 providing overall habitat gains. To analyze the sensitivity of accessibility estimates, input

213 parameters were varied in terms of a) resistance values adapted to fish life stage, b)

214 mobility coefficients and c) probability transformation functions.

215

216 Study area 
217 The Mérantaise is a first order stream draining a $31 \mathrm{~km}^{2}$ catchment located $23 \mathrm{~km}$ south218 west of Paris, in the Ile-de-France region. It is a tributary of the Yvette River belonging to 219 the Seine River catchment (Figure 1a) (4843'45"; $\left.2^{\circ} 06^{\prime} 02^{\prime \prime}\right)$. The Mérantaise was 220 identified as a priority stream, as it provides a high potential of spawning habitat for 221 brown trout population restricted to a segment located downstream of an impassable mill 222 weir (B3) (Figure 2). This stream is also considered as a reservoir of biological diversity 223 bordered by wetlands and includes twenty-height terrestrial and aquatic protected species.

224 Because of a long history of human impacts, the course of the stream is lined with several 225 barriers originating from hydraulic structures (mill weirs) dating from the XIII to XIX 226 century. The focus of this study is a $6 \mathrm{~km}$-long segment of the Mérantaise contained 227 within the Haute Vallée de Chevreuse Natural Regional Park. This stream segment is 228 around 2-5 m-wide, its maximum depth in pools at low flow is approximately $1.0 \mathrm{~m}$. The 229 channel is generally incised, the average slope is $0.75 \%$ and the dominant substrate varies 230 from mixtures of silt and sand to gravel and cobbles.

232 Field survey

233 Habitat characterization

234 Hydromorphological units (HMU) along the stream profile were visually delimited and 235 mapped based on geomorphology and flow type (Newson et al., 1998). Riffle constituted $2365 \%$, runs $28 \%$, glides $55 \%$ and pools $7 \%$ of the total area (Figure $1 \mathrm{~b}$ ). Twelve barriers, 237 potentially restricting fish mobility, were identified, including three impassable mill weirs 238 (1.0-1.5 m high, B3, B11 and B12) and nine barriers (0.1 m and $0.5 \mathrm{~m}$ high) created by 239 culverts, crossing of waste water pipes and an old washhouse. Concave underbanks, 
240 presence of roots, boulders and aquatic plants, considered to be potential trout shelters,

241 were visually identified and georeferenced using a handheld Garmin GPSMAP $62( \pm 5$

$242 \mathrm{~m})$. Potential spawning grounds were identified and georeferenced at low flow on the

243 basis of substrate size and HMU, with the expert assistance of a river technician, highly

244 experienced in counting trout redds in the PNRHVC streams.

\section{$245 \quad$ Fish movement}

246 Between March 2012 and April 2013, thirty-nine individuals were tracked using radio-

247 telemetry in the $2 \mathrm{~km}$-long downstream section of the study segment, limited by the

248 impassable barrier B3. Fish were caught by electrofishing, anesthetized (10\% eugenol

249 solution), weighed, measured and tagged intra-peritoneally with radio transmitters

250 (ATS ${ }^{2}$ models F1020, F1040, and F1170 with encapsulated antenna) using the protocol

251 defined by Gosset et al., (2006). Location of individuals was monitored (i) continuously

252 using two fixed-point receivers (ATS ${ }, \mathrm{R} 4500 \mathrm{~S})$ installed on barriers and (ii) once a

253 week with mobile receivers. Scales were collected to determine age and size at first

254 reproduction. As all age $3+$ and older trout presented spawning marks, it was further

255 assumed that first reproduction occurred at age 2+. The body length (BL) of immature

$256(1+$ non-spawners, $\mathrm{n}=10)$ trout ranged from 178 to $226 \mathrm{~mm}$ and $\mathrm{BL}$ of mature trout $(2+$

257 and older, spawners, $\mathrm{n}=29$ ) varied between 221 to $554 \mathrm{~mm}$.

259 Data analysis

$260 \quad$ Habitat mapping

261 Potential spawning habitat patches were mapped based on georeferenced data using 262 ArcGIS® (ESRI, 2011). Daily-use habitats were modeled using radio-telemetry data 
263 (outside the spawning season) and three spatial metrics: distance to pools (DP), distance 264 to riffles (DR) and distance to shelters (DS), generated with Anaqualand 2.0. The three 265 spatial metrics had proved to be predictors of the presence of trout in headwater streams 266 of Ile-de-France (Le Pichon et al., 2013), as the proximity of pools and riffles tend to 267 provide fish with refuge and feeding opportunities (Ovidio, 1999, Ovidio et al., 2002, 268 Armstrong et al., 2003). A generalized linear model was built to predict daily-use habitat 269 using DS, DP and DR extracted at every radio-telemetry fish location and at every point 270 of an equally-sized pseudo absence dataset generated randomly throughout the river 271 segment $(S=-0.116-(0.099 * D S)-(0.445 * D P)+(0.0248 * D R)(p=0.891,0.023,0.003$,

$2720.069)$ ). To delineate discrete habitat patches, the raster map values were reclassified as a 273 binary map using a probability threshold of 0.4 . The resulting longitudinal distribution of 274 the spawning and daily habitat patches are presented in Figure 1c.

$275 \underline{\text { Resistance maps }}$

276 Raster maps of resistance, quantifying how trout mobility may be restricted by physical 277 barriers, variable swimming energy costs and perceived predation risk, were created 278 combining three variables: HMU (five types), barriers $(\mathrm{N}=12)$ and shelters 279 (presence/absence). HMU, the twelve barriers and the shelters (5 $\mathrm{m}$ diameter circular 280 buffer) were combined to yield 34 possible categories representing the five HMU and the 281 twelve barriers with and without shelters. These classes will be further referred to as 282 mesohabitats. Finally, thirteen resistance maps were generated according to the 283 successive barrier removal scenarios (Figure 3). 


\section{Resistance value assignation}

287 Resistance values were determined using a simple model in which normalized values 288 were assigned to HMU by expert opinion, by combining energy costs and predation risk 289 (Table 1). Resistance values associated with energy costs were based on the assumption 290 that resistance increases with flow velocity while predation risk decrease with shelter

291 presence and HMU average depth, as deep flow provides better cover for salmonids than 292 shallow flow (Rosenfeld and Boss, 2001) (Table 1). Resistance yielded values ranging 293 between 0 and 10 , calculated as $\mathrm{R}=\log (1 /($ energy expenses * average depth * shelters).

294 Similarly, resistances were assigned to barriers based on their height and on their 295 passability (Baudoin et al., 2014). Arbitrary high resistance values (2000) were assigned 296 to the three weirs considered impassable (B3, B11 and B12) while resistance attributed to 297 other barriers ranged between 20 and 150. Two separate sets of resistance values were 298 generated for the two fish classes: mature fish (body length $>230 \mathrm{~mm}$ ), corresponding to 299 the average length of brown trout at maturity in the study stream, and immature fish 300 (body length $<230 \mathrm{~mm}$ ). For a discussion of alternative methods to determine 301 resistances, see (Beier et al., 2008).

302 Brown trout mobility coefficient $(\alpha)$

303 Home range extents (distance between the two most distant locations), further used as 304 mobility coefficients $(\alpha)$, were estimated from telemetry data. Home range extents were 305 estimated 1) outside the spawning period for immature fish (mean: $143 \mathrm{~m}, 85^{\text {th }}$ 306 percentile: $338 \mathrm{~m}$, max: $366 \mathrm{~m}$ ) and mature fish (mean: $170 \mathrm{~m}, 85^{\text {th }}$ percentile: $398 \mathrm{~m}$, 307 max: $774 \mathrm{~m}$ ) and 2) during the spawning period for mature fish (mean: $351 \mathrm{~m}, 85^{\text {th }}$ 308 percentile: $710 \mathrm{~m}$, max: $830 \mathrm{~m})$. 
309 Habitat accessibility

310 Resistance and functional habitats maps were used to compute functional distance maps

311 expressing at each pixel the least cost for reaching 1) a daily-use habitat from the

312 downstream end of the study section; 2) a spawning habitat from the downstream end of

313 the study section and 3) a spawning habitat from a daily-use habitat. These analyses

314 aimed to compare how easily immature and mature trout can complete their life cycle

315 under different barrier removal scenarios. For each of these analyses, functional distances

316 were then converted to accessibility (probability ranging between 0 and 1) using the

317 mobility coefficients and two transformation curves (Figure 3). Although stream

318 salmonids generally tend to exhibit a spatial behaviour better described by a decreasing

319 exponential (fewer fish moving long distances), this pattern is not always consistent

320 (Rodriguez, 2002). Therefore, a Gaussian transformation was also performed as part of a

321 sensitivity analysis.

322 Connected functional habitat area

323 To quantify and visualize the overall accessibility, connected daily-use habitat area

324 (CDHA), connected spawning habitat area (CSHA) and spawning habitat area connected

325 to daily-use habitats (CS2DHA) were estimated as $\sum A c_{i} \times A_{i}$, for $\mathrm{i}=1$ to $\mathrm{N}$ (Number of

326 pixels of the corresponding habitat) where $A_{c i}$ stands for the accessibility of a pixel and

$327 \mathrm{~A}_{\mathrm{i}}$ to pixel area. CDHA was calculated for immature and mature fish while CSHA and

328 CS2DHA were calculated for mature fish.

329

330 Results 
331 Cumulative longitudinal profile of (CSHA), accumulated along the longitudinal profile of

332 the stream from downstream to upstream, gives a quantitative estimate of the overall

333 availability of spawning habitat patches weighted by their accessibility for the mature

334 trout under different barrier management scenarios and different levels of trout mobility

335 (Figure 4). Under the scenario of maintaining all barriers, $500 \mathrm{~m}^{2}$ of CSHA were

336 estimated to be available in the first $1500 \mathrm{~m}$ of the stream profile for the fish of average

337 mobility ( $\alpha=$ mean) (Figure 4$)$. Allowing fully free passage additionally increased CSHA

338 for the latter by only $80 \mathrm{~m}^{2}$. Furthermore, the habitat gain was associated with improved

339 connectivity only to spawning habitats located in the first $2200 \mathrm{~m}$, as independently of

340 the barrier presence. In contrast, for the fish of higher mobility $\left(\alpha=85^{\text {th }}\right.$ percentile and

$341 \alpha=\max$ scenarios), allowing free passage both increased connectivity and provided

342 access to spawning habitats located upstream. This was particularly relevant for spawning

343 habitats located between 1500 and $2000 \mathrm{~m}$ and to a lesser degree to those between 4000

344 and $5000 \mathrm{~m}$ upstream of the lower end of the study segment (Figure 4).

345 To estimate the potential gain related to removing each barrier, the total CSHA (Figure 5)

346 and CDHA (Figure 6) were also quantified for successive barrier removal scenarios.

347 While removing the first two barriers did not increase accessibility to CSHA, eliminating

348 the third barrier B3 yielded between 155 and $245 \mathrm{~m}^{2}$ of additional connected spawning

349 habitats for mobile trout $\left(\alpha=85^{\text {th }}\right.$ percentile and $\left.\alpha=\max \right)$. Then, removing barriers B5 to

350 B8 provided access to a reach containing further suitable spawning habitats, whereas

351 removing $\mathrm{B} 9$ to $\mathrm{B} 12$ did not increase CSHA (Figure 5). All together for the mobile

352 fraction of the trout population ( $\alpha=85^{\text {th }}$ percentile and $\alpha=$ max), spawning habitat

353 connectivity index was increased from $31 \pm 2 \%$ with all barriers maintained in place to 
$35444 \pm 3 \%$ in free passage conditions. In contrast to the results on the CSHA, the potential 355 gains in connected daily-use habitat area (CDHA) for the Mérantaise related to the 356 successive barrier removal were relatively low and varied significantly between fish of 357 different mobility (Figure 6). Removing barriers did not increase the CDHA for lower 358 mobility fish ( $\alpha=$ mean) of both size. With high mobility coefficient $\left(\alpha=85^{\text {th }}\right.$ percentile), 359 an increase of CDHA is observed for both size with the Gaussian transformation 360 function. With the very high mobility coefficient $(\alpha=\max )$, a potential gain in CDHA 361 ranging from $2 \%$ to $10 \%$ was associated with a free passage between B3 and B8 for 362 immature fish with Gaussian transformation function and for mature fish.

363 With all barriers present, the longitudinal profile of spawning habitat accessibility 364 displayed a decrease in probability of access from 1 to 0.5 from the downstream end of 365 the study reach up to B3, after which the accessibility becomes close to null (Figure 7a).

366 Allowing free fish passage up to B4 provided access to two large patches of spawning 367 habitats located between B3 and B4 (Figure 7b). Lower gains in accessibility were also 368 obtained in the segment between B10 and B11. The removal of barriers B4 to B8 only 369 slightly increased the accessibility to spawning habitats located upstream starting from $370 \mathrm{~B} 6$ and between B10 and B11 (Figure 7c). Removing the remaining barriers did not 371 improve further habitat accessibility (Figure 7d).

372 Overall, even with all barriers present spawning habitat patches in the Mérantaise are 373 generally well connected to daily-use habitats, with accessibility values estimated to be 374 over 0.5 for all patches except those located between B3 and B4 (Figure 8 a). Removing 375 B1 to B4 increased CS2DHA by $140 \mathrm{~m}^{2}(6 \%)$ (Figure $\left.8 \mathrm{~b}\right)$. Removing further barriers did 
376 not provide access to otherwise unreachable habitats, but only slightly increased

377 accessibility values to a few spawning patches (Figure $8 \mathrm{c}-\mathrm{d}$ ).

378

379 Discussion

380 The presented approach of quantifying connectivity in streams and rivers is novel,

381 adapting a two-dimensional functional landscape model (Adriaensen et al., 2003) to

382 stream ecology and integrating fish movement directionality. This approach provides

383 means to incorporate the behavioural component of connectivity by including fish

384 mobility at specific life stages, a challenge highlighted by Fullerton et al. (2010).

385 Furthermore, the map-based approach might be more suitable than graph-based dendritic

386 network approaches (Saura and Torné, 2009, Van Looy et al., 2014, Segurado et al.,

387 2015) to account for longitudinal and lateral movements along the riverscape and the $2 \mathrm{D}$

388 physical heterogeneity of rivers. These features are of great importance as they allow

389 continuous mapping of habitat variability in a context relevant to particular species and

390 life stages at the intermediate scale of management actions (Le Pichon et al., 2016) that

391 cannot be substituted by discrete data typically obtained from sampling multiple smaller

392 reaches (Fausch et al., 2002, White et al., 2014). Moreover, the presented continuous

393 approach could be complementary with large-scale riverscape approaches, using network

394 drainage lines, for species such as wild salmon whose life-cycle involves movements

395 across large geographic areas (Whited et al., 2012). However, estimating habitat

396 connectivity requires defining resistances and suitable habitat patches at a scale that is

397 relevant to the species and life stages of interest. Therefore, grain size should preferably

398 be smaller than the size of habitat patches and several times smaller than the species 
399 capacity of movement. Furthermore, the extent should be larger than the species capacity

400 of movement. The method could be used to examine the small scale mobility of larvae in

401 a reach using a fine scale hydrodynamic model as resistance as well as whale migration

402 in an estuary dominated by large scale tidal currents. Although a limitation of the method

403 consists in obtaining continuous data at the appropriate scale, such 2D riverscape scale

404 data is becoming increasingly available at lower costs through high resolution remote

405 sensing of water temperature (Dugdale et al., 2013), bathymetry (Legleiter et al., 2009),

406 substrate granulometry (Carbonneau et al., 2005) and flow velocity (Tamminga et al.,

407 2015, Hugue et al., 2016).

408 Along with the general benefits of restoring ecological continuity, stream specific 409 quantitative estimates of increase in habitat accessibility obtained through this raster410 based method might provide managers and local decision makers with additional 411 convincing arguments in favor of undertaking stream restoration efforts. Indeed, recently 412 used in a multi-agent platform, connectivity estimates has contributed to overcome water 413 use conflicts by providing a shared vision of the river (Carre et al. 2014).

415 Through the Water Framework Directive, European countries are recognizing the 416 problem of aquatic habitat fragmentation and allocating budgets to progressively restore 417 river channels and, where necessary, build structures to allow fish passage. Several 418 methods have been recently suggested for prioritizing barrier removal including scoring 419 and ranking barriers, stepwise scoring and ranking, scenario analysis, optimization, or 420 complete enumeration (see McKay et al. 2016 for review). Anaqualand is well suited to 421 perform scenario analyses and can handle either continuous or binary estimates of barrier 
422 permeability. The assessment of the cumulative impacts of multiple barriers possible with

423 the software would help prioritizing barrier removal (Branco et al., 2014, Cote et al., 424 2009) with better efficiency than scoring-and-ranking approaches (Kemp and O'Hanley, 425 2010).

426 In this study, connectivity was expressed in terms of connected habitat, providing a 427 decision support tool to compare different scenarios rather than precise estimates of 428 probability of access. In the light of the conducted analysis, efforts in the case of 429 Mérantaise should be concentrated on improving the passability of B3 barrier in order to 430 both increase the area of accessible spawning habitats by $13 \%$ of the total habitat area for 431 mobile trout and maximize the connectivity between spawning habitat and daily-use 432 habitat patches. Such change is favorable, as improved connectivity between spawning 433 and daily-use habitats might increase probability of habitat use (Flitcroft et al., 2012). 434 However, removing further barriers upstream would only slightly increase the total 435 accessible habitat area due to more passable barriers and to the lower availability of 436 functional habitats in this upstream reach. Therefore, the removal or modification of these 437 barriers might be considered to be of low priority in terms of brown trout habitat 438 management and conservation. Nevertheless, although removing barriers did not increase 439 CDHA for lower mobility fish, removing barriers might improve future CDHA for these 440 fish, as mobile fish will spawn in the upstream area and produce low mobility fish that in 441 turn will use available daily use habitats.

442 Overall, caution must be taken when interpreting the results as they are affected by the 443 choice of several parameters, such as the estimates of up- and downstream mobility, 444 resistance assigned to barriers and probability distribution functions. For instance, the 
445 resistance assigned to barriers could vary according to water discharge and have an 446 impact on connectivity for brown trout (Denic and Geist 2010). Furthermore, since there

447 is a generally fairly high uncertainty associated with these input parameters, in addition to 448 estimating connectivity for a plausible range of mobility parameters, it might be 449 appropriate to assess the sensitivity of the results to different resistance model 450 formulations and to interpret the results accordingly. In recent decades, knowledge of 451 mobility behaviour and of the characteristics affecting barrier passability for many 452 species has improved significantly (Ovidio and Philippart, 2002, Baudoin et al., 2014).

453 Nevertheless, more field studies quantifying the effect of physical habitat on fish mobility 454 are still needed in order to properly calibrate spatially variable resistance to movement at 455 different fish size and life stages. In cases where resistance values are unavailable, 456 connectivity can still be estimated using a distance and mobility data only. In the future 457 application of the model, it should also be considered that in parallel to increasing 458 connectivity, additional benefits of barrier removal can include restoring channel 459 morphology and bed granulometry. Such possible changes in both upstream and 460 downstream habitats were not taken into account in this case study, but could be 461 addressed by coupling Anaqualand with a two-dimensional hydraulic modelling.

462 Anaqualand could be useful for future work aiming at improving estimates of stream 463 carrying capacities, in particular for species exhibiting distinct ontogenic shifts in habitat 464 requirements during their life cycle. For instance, for brown trout, estimating 465 successively the connectivity of adult daily use habitats to spawning habitats, of 466 connected spawning to nursery habitats and of connected nursery habitats to juvenile 467 daily use habitats might be useful to get a portrait of how habitats are linked through the 
468 life cycle. Comparing the habitat connectivity levels associated with each life stage might

469 help to identify bottlenecks caused by habitat limitation and obtain better estimates of

470 carrying capacity. Furthermore, the approach could also be used to improve habitat

471 quality models of species using complementary habitats over a daily cycle, such as

472 feeding habitats and shelters. This paper presented a case applied to fish but the method

473 could as well be applied to other mobile organisms which dispersal is restricted by

474 natural or anthropogenic constraints, such as aquatic invertebrates (Datry et al., 2016).

475 Overall, Anaqualand may become a timely tool particularly helpful to fisheries managers,

476 as evidence showing the critical importance of connectivity between habitats used

477 throughout the life cycle for the productivity and persistence of fish populations is

478 accumulating (Flitcroft et al., 2012, Falke et al., 2013, Bergeron et al. 2016). Finally, in

479 addition to increased accessible habitat area as assessed in this case study, prioritisation

480 of management efforts might also be established based on issues related to costs, the

481 social context, local politics and to the cultural heritage designation associated with

482 particular streams or historical obstacles (most often mill weirs; Kemp and O'Hanley, 483 (2010).

\section{Acknowledgments}

486 We are grateful to Evelyne Tales, Aurélia Mathieu, Amandine Zahm, Mathieu Girondin, 487 Daniel Mira and Adrien Rey for their invaluable assistance in carrying out fieldwork. 488 This manuscript was much improved thanks to the thoughtful reviews of Maria Alp and 489 Evelyne Tales, Philip Boon and two anonymous reviewers. The study received funding 490 from the Haute Vallée de Chevreuse Natural Regional Park, the French National Agency 
1

2

3

4

5

6

7

8

9

10

11

12

13

14

15

16

17

18

19

20

21

22

23

24

25

26

27

28

29

30

31

32

33

34

35

36

37

38

39

40

41

42

43

44

45

46

47

48

49

50

51

52

53

54

55

56

57

58

59

60
491 for Water and Aquatic Environments (ONEMA) and the CNRS scientific program

492 'Piren-Seine'. We are also thankful to Commission permanente de coopération franco-

493 québécoise and the ministere des Relations Internationales du Québec for providing a

494 travel stipend. 
495

496

497

498

499

500

501

502

503

504

505

506

507

508

509

510

511

512

513

514

515

516

517

518

519

520

521

522

523

524

525

526

527

528

529

530

531

532

533

534

535

536

537

538

539

\section{References}

Adriaensen F, Chardon JP, De Blust G, Swinnen E, Villalba S, Gulinck H, Matthysen E. 2003. The application of 'least-cost' modelling as a functional landscape model. Landscape and Urban Planning 64: 233-247.

Armstrong J, Kemp P, Kennedy G, Ladle M, Milner N. 2003. Habitat requirements of Atlantic salmon and brown trout in rivers and streams. Fisheries Research 62: 143-170.

Baudoin, J.-M., Burgun, V., Chanseau, M., Larinier, M., Ovidio, M., Sremski, W., Steinbach, P., Voegtle, B., 2014. Informations sur la Continuité Ecologique-ICE, Evaluer le franchissement des obstacles par les poissons. Principes et méthodes. Onema, Paris. 204pp.

Baudry J, Merriam HG. 1988. Connectivity and connectedness: functional versus structural patterns in landscapes. In Connectivity in Landscape Ecology, Schreiber KF (ed). in Schreiber, K. F. ed. Connectivity in landscape ecology, Proceedings of the 2nd International Association for Landscape Ecology. Munstersche Geographische Arbeiten 29, p.23-28.

Beier P, Majka DR, Spencer WD. 2008. Forks in the Road: Choices in procedures for designing wildland linkages. Conservation Biology 22: 836-851.

Bergeron N, Roy M, Le Pichon C, Gillis CA, Bujold JN, Mingelbier M, 2016. Functional habitat chronology analysis: integrating life stages habitat requirements and habitat connectivity for estimating river production potential. Paper 26203 in, Webb JA, Costelloe JF, Casas-Mulet R, Lyon JP, Stewardson MJ (eds.) Proceedings of the 11th International Symposium on Ecohydraulics. Melbourne, Australia, 7-12 February 2016. The University of Melbourne, ISBN: 97807340 53398.

Branco P, Segurado P, Santos JM, Ferreira MT. 2014. Prioritizing barrier removal to improve functional connectivity of rivers. Journal of Applied Ecology 51: 11971206.

Carbonneau PE, Bergeron N, Lane SN. 2005. Automated grain size measurements from airborne remote sensing for long profile measurements of fluvial grain sizes. Water Resources Research 41: 1-9, W11426 (doi: 10.1029/2005WR003994).

Carre C, Haghe J-P, De Coninck A, Becu N, Deroubaix J, Pivano C, Flipo N, Le Pichon C, Tallec G. 2014. How to integrate scientific models in order to switch from flood control river management to multifunctional river management? International Journal of River Basin Management 12: 1-30.

Cote D, Kehler D, Bourne C, Wiersma Y. 2009. A new measure of longitudinal connectivity for stream networks. Landscape Ecology 24: 101-113.

Council of the European Communities. 2000. Directive 2000/60/EC of the European Parliament and of the Council of 23 October 2000 establishing a framework for Community action in the field of water policy. Official Journal of the European Communities.

Datry T, Pella H, Leigh C, Bonada N, Hugueny B. 2016. A landscape approach to advance intermittent river ecology. Freshwater Biology 61: 1200-1213.

Davies NB, Krebs JR, West SA. 2012. An introduction to behavioural ecology. John Wiley \& Sons. 
Denic M, Geist J. 2010. Habitat suitability analysis for lacustrine brown trout (Salmo trutta) in Lake Walchensee, Germany: implications for the conservation of an endangered flagship species. Aquatic Conservation: Marine and Freshwater Ecosystems 20: 9-17.

Dugdale SJ, Bergeron NE, St-Hilaire A. 2013. Temporal variability of thermal refuges and water temperature patterns in an Atlantic salmon river. Remote Sensing of Environment 136: 358-373.

Elosegi A, Diez J, Mutz M. 2010. Effects of hydromorphological integrity on biodiversity and functioning of river ecosystems. Hydrobiologia 657: 199-215.

Eros T, Schmera D, Schick RS. 2011. Network thinking in riverscape conservation - A graph-based approach. Biological Conservation 144: 184-192.

ESRI 2011. ArcGIS Desktop: Release 10. Redlands, CA: Environmental Systems Research Institute.

Fahrig L, Merriam G. 1994. Conservation of Fragmented populations. Conservation Biology 8: 50-59.

Falke JA, Dunham JB, Jordan CE, McNyset KM, Reeves GH. 2013. Spatial ecological processes and local factors predict the distribution and abundance of spawning by Steelhead (Oncorhynchus mykiss) across a complex riverscape. Plos One 8, e79232, 1-11.

Fausch KD, Torgersen CE, Baxter CV, Li HW. 2002. Landscapes to riverscapes: Bridging the gap between research and conservation of stream fishes. BioScience 52: 483-498.

Flitcroft RL, Burnett KM, Reeves GH, Ganio LM. 2012. Do network relationships matter? Comparing network and instream habitat variables to explain densities of juvenile coho salmon (Oncorhynchus kisutch) in mid-coastal Oregon, USA. Aquatic Conservation: Marine and Freshwater Ecosystems 22: 288-302.

Fullerton AH, Burnett KM, Steel EA, Flitcroft RL, Pess GR, Feist BE, Torgersen CE, Miller DJ, Sanderson BL. 2010. Hydrological connectivity for riverine fish: measurement challenges and research opportunities. Freshwater Biology 55: 2215-2237.

Gangloff MM. 2013. Taxonomic and ecological tradeoffs associated with small dam removals. Aquatic Conservation: Marine and Freshwater Ecosystems 23: 475480.

Gilbert-Norton L, Wilson R, Stevens JR, Beard KH. 2010. A meta-analytic review of corridor effectiveness. Conservation Biology 24: 660-668.

Giske J, Huse G, Fiksen O. 1998. Modelling spatial dynamics of fish. Reviews in Fish Biology and Fisheries 8: 57-91.

Gosset C, Rives J, Labonne J. 2006. Effect of habitat fragmentation on spawning migration of brown trout (Salmo trutta L.). Ecology of Freshwater Fish 15: 247254.

Hanski I. 1994. A practical model of metapopulation dynamics. Journal of Animal Ecology 63: 151-162.

Hugue F, Lapointe M, Eaton BC, Lepoutre A. 2016. Satellite-based remote sensing of running water habitats at large riverscape scales: Tools to analyze habitat heterogeneity for river ecosystem management. Geomorphology 253: 353-369. 
585

586

587

588

589

590

591

592

593

594

595

596

597

598

599

600

601

602

603

604

605

606

607

608

609

610

611

612

613

614

615

616

617

618

619

620

621

622

623

624

625

626

627

628

629
Jensen OP, Christman MC, Miller TJ. 2006. Landscape-based geostatistics: a case study of the distribution of blue crab in Chesapeake Bay. Environmetrics 17: 605-621.

Jonsson, B \& Jonsson, N. (2011) Ecology of Atlantic salmon and brown trout: Habitat as a template for life histories. Fish and Fisheries Series 33, Springer, Dordrecht, The Netherlands, $708 \mathrm{pp}$.

Kanno Y, Letcher BH, Coombs JA, Nislow KH, Whiteley AR. 2014. Linking movement and reproductive history of brook trout to assess habitat connectivity in a heterogeneous stream network. Freshwater Biology 59: 142-154.

Kemp PS, O'Hanley JR. 2010. Procedures for evaluating and prioritising the removal of fish passage barriers: a synthesis. Fisheries Management and Ecology 17: 297322.

Knaapen JP, Scheffer M, Harms B. 1992. Estimating habitat isolation in landscape planning. Landscape and Urban Planning 23: 1-16.

Le Pichon C, Gorges G, Faure T, Boussard H. 2006. Anaqualand 2.0 : freeware of distances calculations with frictions on a corridor. In. Cemagref: Antony; https:/www6.rennes.inra.fr/sad/Outils-Produits/Outils-informatiques/Anaqualand.

Le Pichon C, Talès E, Clément F, Leclerc N, Gorges G, Zahm A. 2013. Effet des discontinuités physiques sur la distribution spatiale des poissons en tête de bassin : cas de l'Orgeval. In L'observation long terme en environnement: Exemple du bassin versant de l'Orgeval. Editions QUAE: Versailles.

Le Pichon C, Tales É, Gorges G, Baudry J, Boët P. 2016. Using a continuous riverscape survey to examine the effects of the spatial structure of functional habitats on fish distribution. Journal of Freshwater Ecology 31: 1-19.

Legleiter CJ, Roberts DA, Lawrence RL. 2009. Spectrally based remote sensing of river bathymetry. Earth Surface Processes and Landforms 34: 1039-1059.

McKay, S. K., Cooper, A. R., Diebel, M. W., Elkins, D., Oldford, G., Roghair, C., and Wieferich, D. 2016. Informing watershed connectivity barrier prioritization decisions: A Synthesis. River Research and Applications, doi: 10.1002/rra.3021.

McKean J, Nagel D, Tonina D, Bailey P, Wright CW, Bohn C, Nayegandhi A. 2009. Remote sensing of channels and riparian zones with a narrow-beam aquaticterrestrial LIDAR. Remote Sensing 1: 1065-1096.

Merenlender AM, Matella MK. 2013. Maintaining and restoring hydrologic habitat connectivity in mediterranean streams: an integrated modeling framework. Hydrobiologia 719: 509-525.

Moilanen A, Leathwick J, Elith J. 2008. A method for spatial freshwater conservation prioritization. Freshwater Biology 53: 577-592.

Mühlner S, Kormann U, Schmidt-Entling M, Herzog F, Bailey D. 2010. Structural versus functional habitat connectivity measures to explain bird diversity in fragmented orchards. Journal of Landscape Ecology 3: 52-64.

Newson MD, Harper DM, Padmore CL, Kemp JL, Vogel B. 1998. A cost-effective approach for linking habitats, flow types and species requirements. Aquatic Conservation: Marine and Freshwater Ecosystems 8: 431-446.

Ovidio M. 1999. Annual activity cycle of adult brown trout (Salmo trutta L.): A radiotelemetry study in a small stream of the Belgian Ardenne. Bulletin francais de la peche et de la pisciculture 352: 1-18. 
Ovidio M, Baras E, Goffaux D, Giroux F, Philippart JC. 2002. Seasonal variations of activity pattern of brown trout (Salmo trutta) in a small stream, as determined by radio-telemetry. Hydrobiologia 470: 195-202.

Ovidio M, Philippart JC. 2002. The impact of small physical obstacles on upstream movements of six species of fish - Synthesis of a 5-year telemetry study in the River Meuse basin. Hydrobiologia 483: 55-69.

Pringle C. 2003. The need for a more predictive understanding of hydrologic connectivity Aquatic Conservation: Marine and Freshwater Ecosystems 13: 467-471.

Pringle CM, Naiman RJ, Bretschko G, Karr JR, Oswood MW, Webster JR, Welcomme RL, Winterbourn MJ. 1988. Patch dynamics in lotic systems : the stream as a mosaic. Journal of North American Benthological Society 7: 503-524.

Rayfield B, Fortin M-J, Fall A. 2011. Connectivity for conservation: a framework to classify network measures. Ecology 92: 847-858.

Reeves SA, Usher MB. 1989. Application of diffusion-model to the spread of an invasive species:the coypu in Great-Britain. Ecological Modelling 47: 217-232.

Rivers-Moore N, Mantel S, Ramulifo P, Dallas H. 2016. A disconnectivity index for improving choices in managing protected areas for rivers. Aquatic Conservation: Marine and Freshwater Ecosystems 26: 29-38.

Rosenfeld JS, Boss S. 2001. Fitness consequences of habitat use for juvenile cutthroat trout: energetic costs and benefits in pools and riffles. Canadian Journal of Fisheries and Aquatic Sciences 58: 585-593.

Saura S, Torné J. 2009. Conefor Sensinode 2.2: A software package for quantifying the importance of habitat patches for landscape connectivity. Environmental Modelling \& Software 24: 135-139.

Schlosser IJ. 1995. Critical landscape attributes that influence fish population dynamics in headwater streams. Hydrobiologia 303: 71-81.

Segurado P, Branco P, Avelar AP, Ferreira MT. 2015. Historical changes in the functional connectivity of rivers based on spatial network analysis and the past occurrences of diadromous species in Portugal. Aquatic Sciences 77: 427-440.

Statzner B. 1981. The Relation Between' Hydraulic Stress' and Microdistribution of Benthic Macroinvertebrates in a Lowland Running Water System, the Schierenseebroks(North Germany). Archiv für Hydrobiologie 91: 23-33.

Tamminga A, Hugenholtz C, Eaton B, Lapointe M. 2015. Hyperspatial remote sensing of channel reach morphology and hydraulic fish habitat using an unmanned aerial vehicule (UAV): a first assessment in the context of river research and management. River Research and Applications 31: 379-391.

Taylor PD, Fahrig L, Henein K, Merriam G. 1993. Connectivity is a vital element of landscape structure. Oikos 68: 571-573.

Torterotot J-B, Perrier C, Bergeron NE, Bernatchez L. 2014. Influence of forest road culverts and waterfalls on the fine-scale distribution of Brook trout genetic diversity in a boreal watershed. Transactions of the American Fisheries Society 143: $1577-1591$.

Turgeon K, Robillard A, Grégoire J, Duclos V, Kramer DL. 2010. Functional connectivity from a reef fish perspective: behavioral tactics for moving in a fragmented landscape. Ecology 91: 3332-3342. 
676

677

678

679

680

681

682

683

684

685

686

687

688

689

690

691

692

693

694

695

696

697

698

699

Van Looy K, Piffady J, Cavillon C, Tormos T, Landry R, Souchon Y. 2014. Integrated modelling of functional and structural connectivity of river corridors for European otter recovery. Ecological Modelling 273: 228-235.

Vos CC, Verboom J, Opdam PFM, TerBraak CJF. 2001. Toward ecologically scaled landscape indices. American Naturalist 157: 24-41.

White SM, Giannico G, Li H. 2014. A 'behaviorscape' perspective on stream fish ecology and conservation: linking fish behavior to riverscapes. Wiley Interdisciplinary Reviews: Water 1: 385-400.

Whited DC, Kimball JS, Lucotch JA, Maumenee NK, Wu H, Chilcote SD, Stanford JA. 2012. A Riverscape analysis tool developed to assist wild salmon conservation across the North Pacific Rim. Fisheries 37: 305-314.

Wiens JA. 2002. Riverine landscapes: Taking landscape ecology into the water. Freshwater Biology 47: 501-515.

Table 1. Values assigned to predation risk (average depth and shelter) and energy costs associated with each mesohabitat to calculate resistance (R $(R=\log (1 /($ energy costs * predation risk) $)$. Note that higher scores yields lower resistance values.

\begin{tabular}{ccccc}
\hline & Energy costs & Predation risk & Energy costs & Predation risk \\
\hline \multirow{2}{*}{ Immature fish } & 1 & \multicolumn{2}{c}{ Mature fish } \\
Pool & 1 & 1 & 1 & 1 \\
Run & 1 & 0.7 & 1 & 0.5 \\
Riffle head & 0.6 & 0.5 & 0.8 & 0.55 \\
Riffle & 0.45 & 0.6 & 0.7 & 0.45 \\
Shelter (P/A) & 0.4 & $(1 / 0.65)$ & & 0.45 \\
\hline
\end{tabular}


700 Figure 1. Study area, a) Location of the study site (star), the Merantaise stream in the 701 Seine River Basin, b) pseudo three-dimensional representation of the river profile with 702 location of spawning and daily use habitat patches c) longitudinal profile of barriers and 703 hydromorphological units (HMU) indicated as white bars.

704 Figure 2. Mérantaise stream study site. a. View of a riffle during the winter. b. View of 705 the Seuil d'Ors mill weir (B3) during the summer.

706 Figure 3. Flowchart used to model brown trout habitat accessibility. a) Input data, b) 707 Input parameters and c) Connected habitat availability output for the three analyses 708 yielding estimates of 1) connected daily use habitat area (CDHA) from downstream 2) 709 connected spawning habitat area from downstream (CSHA) and 3) connected spawning 710 to daily use habitat area (CS2DHA). Connected habitat availability was estimated for 711 varying functional habitat connectivity $(\mathrm{N}=3)$, scenarios of successive upstream barrier 712 removal $(\mathrm{N}=13)$, fish size for $\operatorname{CDHA}(\mathrm{N}=2)$, mobility coefficients $(\mathrm{N}=3)$ and probability 713 of access transform function $(\mathrm{N}=2)$.

714 Figure 4. Cumulative longitudinal profile of connected spawning habitat area (CSHA) $715\left(\mathrm{~m}^{2}\right)$ accessible to mature trout during the spawning period. Symbol shapes represent 716 degrees of trout mobility: including average (mean), high (p85: $85^{\text {th }}$ percentile) and very 717 high (maximum) mobility; line type corresponds to two management scenarios: with all 718 twelve barriers present (barriers) and in free passage conditions (no barriers); symbol 719 color reflects the probability transform function: Gaussian (ga) or exponential (ex). B1 to 720 B12 indicate barrier locations. " 0 " at the $\mathrm{x}$-axis corresponds to the downstream end of the 721 study segment.

722 Figure 5. Spawning habitat accessibility index, expressing the ratio between the 723 connected spawning habitat area (CSHA) and the total spawning habitat area in 724 percentage, for mature trout. Average mobility trout (mean), high mobility trout (p85: $72585^{\text {th }}$ percentile) and very high mobility trout ( $\left.\max \right)$ are represented by different symbol 726 shapes; symbol color reflects the probability transform function used: Gaussian (ga) or 727 exponential (ex). Grey area displays the envelope of accessibility values for mobile trout $728\left(85^{\text {th }}\right.$ percentile and $\left.\max \right)$. 
729 Figure 6. Daily-use habitat accessibility index, expressing the ratio between the 730 connected daily-use habitat area (CDHA) and the total daily-use habitat area in 731 percentage. Symbol size reflects two fish size classes considered: mature fish (m); and 732 immature trout (i). Symbol type allows to distinguish between average mobility trout 733 (mean), high mobility trout ( $\mathrm{p} 85: 85^{\text {th }}$ percentile) and very high mobility trout ( $\left.\max \right)$, 734 outside the spawning season. Symbol color reflects the probability transform functions 735 used: Gaussian (ga) and exponential (ex). Grey area displays the range of connectivity 736 values for mobile trout $\left(85^{\text {th }}\right.$ percentile and $\left.\max \right)$.

737 Figure 7. Pseudo two-dimensional profile of the accessibility of spawning habitat from 738 the downstream end of the study section. Different management scenarios are presented: 739 a) all barriers are maintained, b) accessibility gain (increase) when removing B1-B4 740 compared to the scenario a), c) accessibility gain when removing B1-B8 compared to the 741 scenario b), d) accessibility gain when removing B1-B12 compared to the scenario c). 742 The cases shown were calculated for mature fish with very high mobility $(\alpha=\max )$ and 743 using the exponential function of decrease in probability of access. B1 to B12 and stars 744 indicated the location of barriers.

745 Figure 8. Pseudo two-dimensional profile of the accessibility of spawning habitat patches 746 from daily use habitat patches located upstream or downstream. Different management 747 scenarios are presented: a) all barriers are maintained, b) accessibility gain (increase) 748 when removing B1-B4 compared to the scenario a), c) accessibility gain when removing 749 B1-B8 compared to the scenario b), d) accessibility gain when removing B1-B12 750 compared to the scenario c). The cases shown were calculated for mature trout with very 751 high mobility ( $\alpha=\max )$ and using the exponential function of decrease in probability of 752 access. B1 to B12 and stars indicated the location of barriers. 
a.

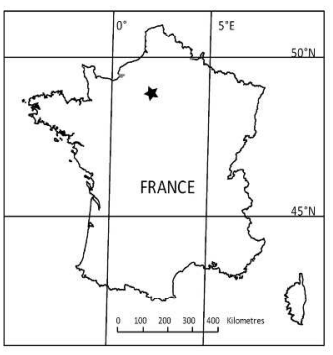

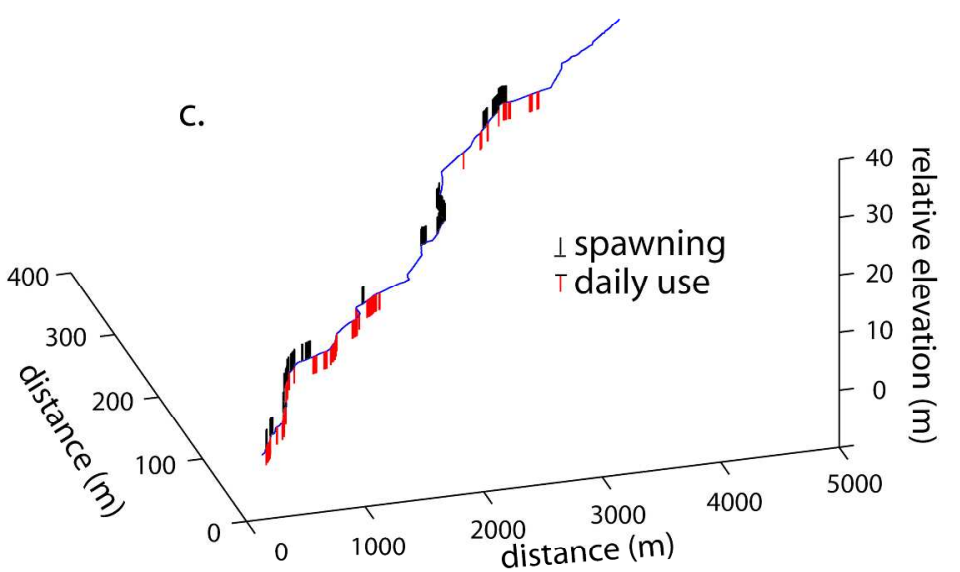

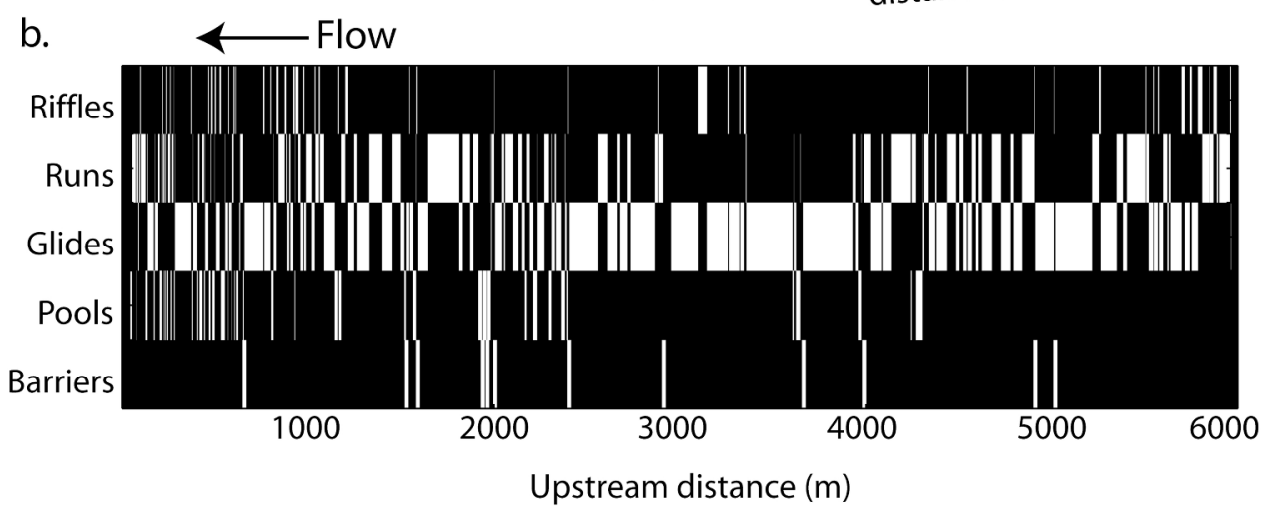

Figure 1

$120 \times 109 \mathrm{~mm}(600 \times 600 \mathrm{DPI})$ 


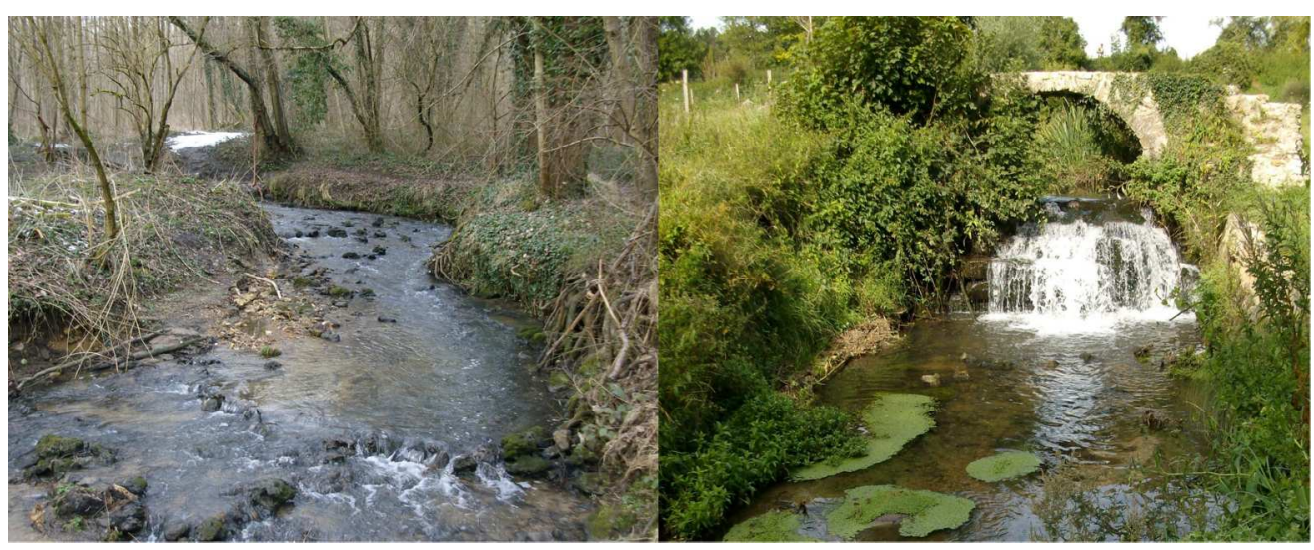

Figure 2

$161 \times 65 \mathrm{~mm}(300 \times 300 \mathrm{DPI})$

23
24
25
26
27
28
29
30
31
32
33
34
35
36
37
38
39
40
41
42
43
44
45
46
47
48
49
50
51
52
53
54
55
56
57
58
59
60


Figure 3 $136 \times 96 \mathrm{~mm}(600 \times 600 \mathrm{DPI})$ 


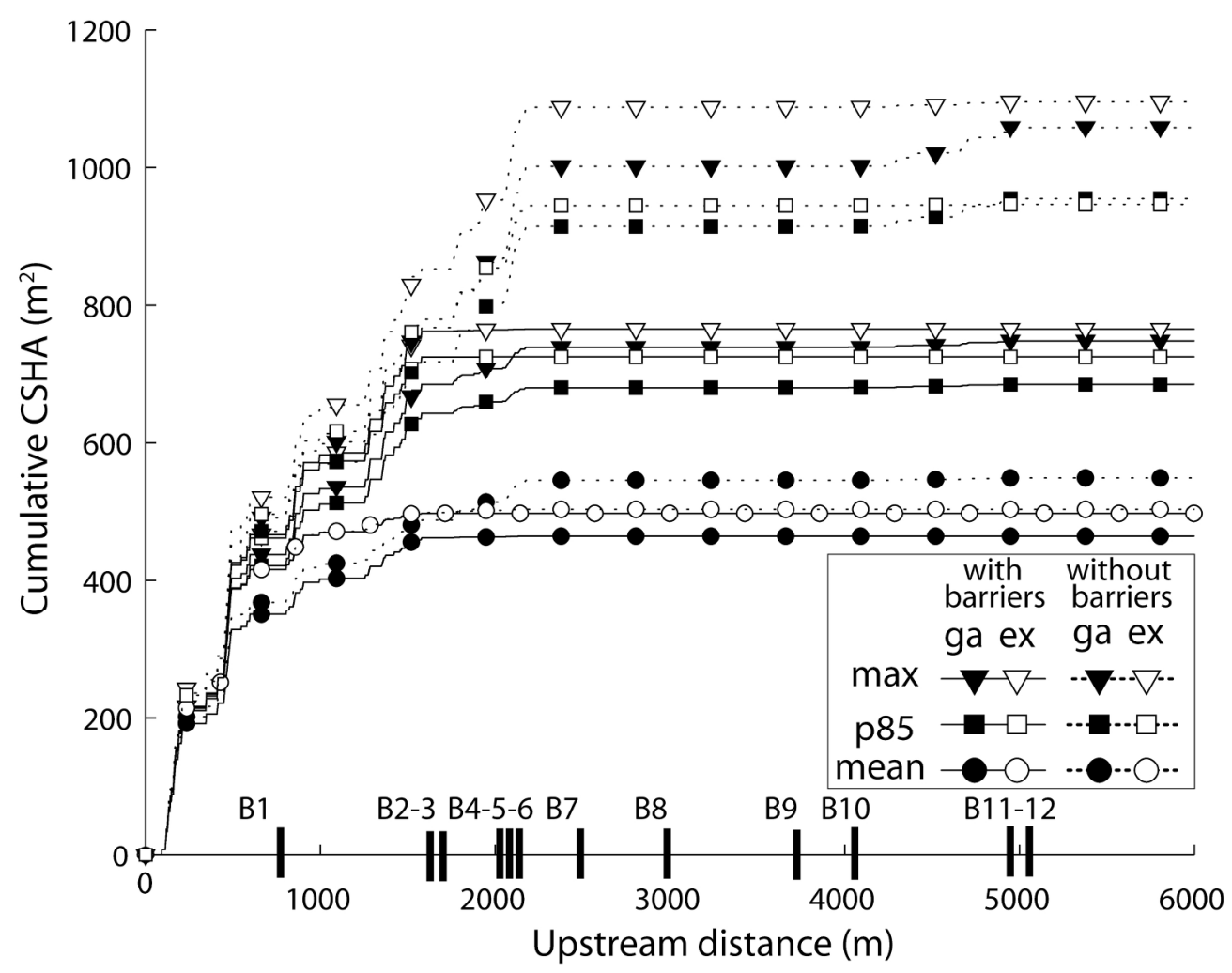

Figure 4 $104 \times 81 \mathrm{~mm}(600 \times 600$ DPI $)$ 


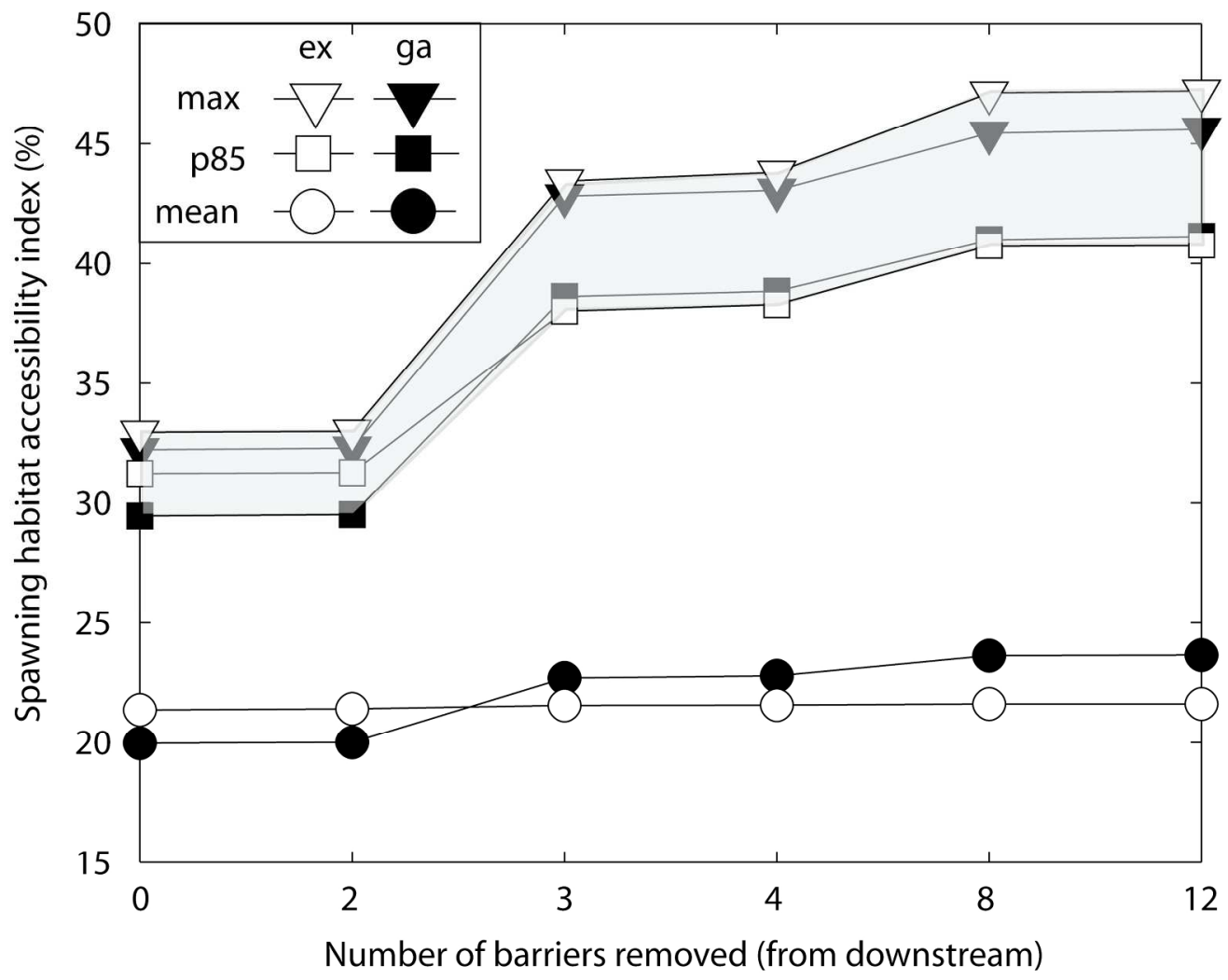

Figure 5 $104 \times 83 \mathrm{~mm}(600 \times 600$ DPI $)$ 


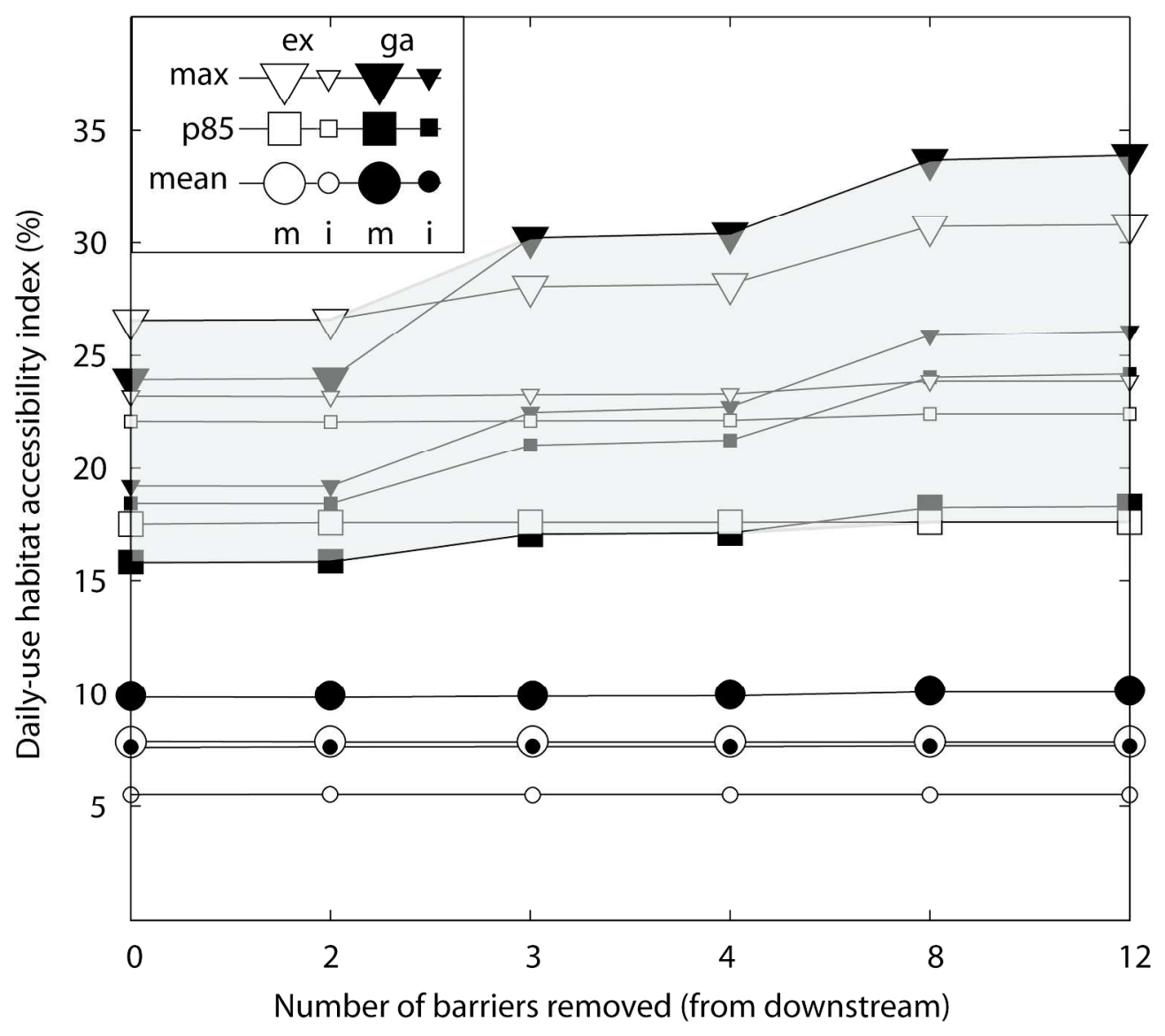

Figure 6 $121 \times 110 \mathrm{~mm}(600 \times 600 \mathrm{DPI})$ 


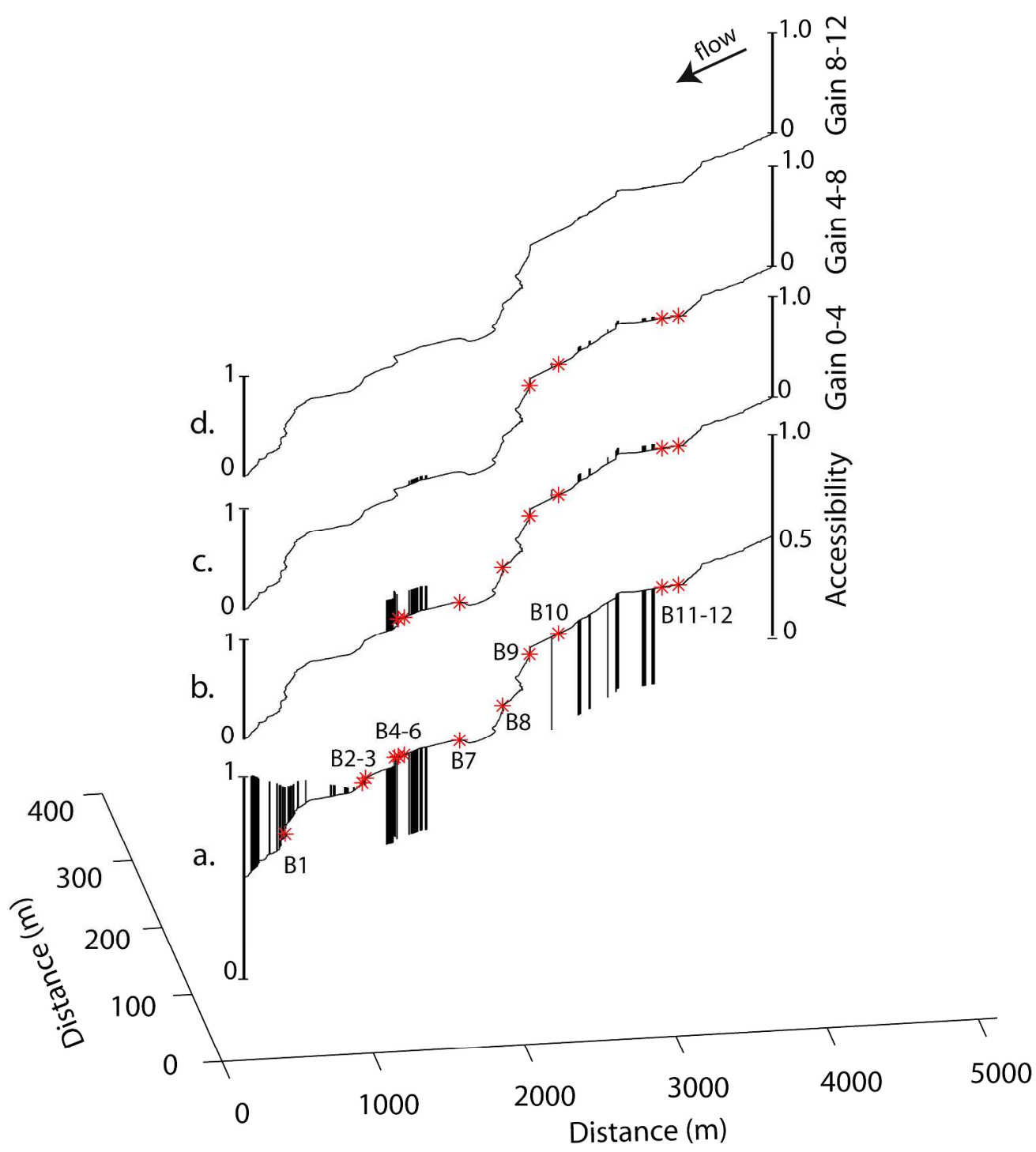

Figure 7

$144 \times 159 \mathrm{~mm}(600 \times 600$ DPI $)$ 


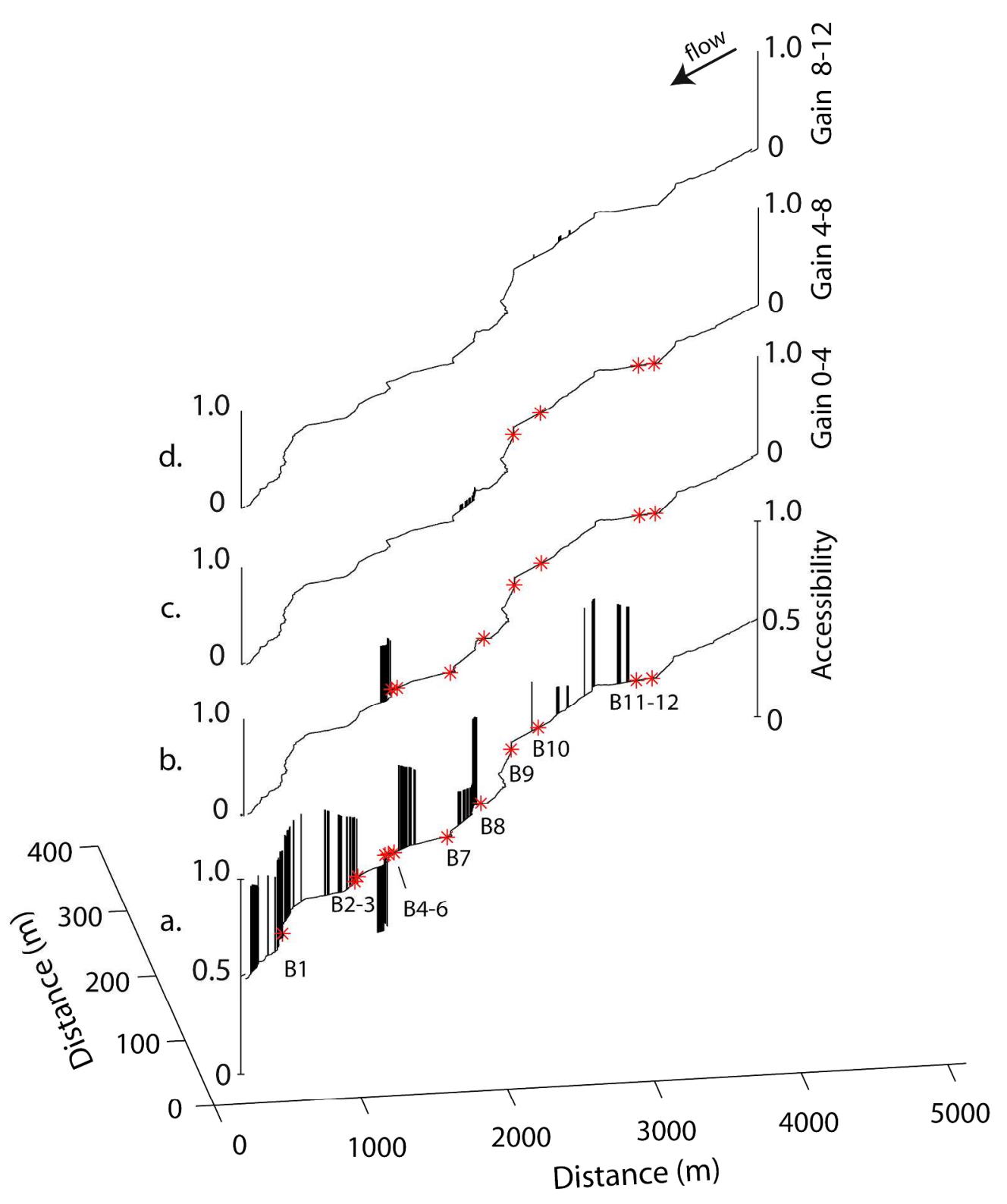

Figure 8

$155 \times 185 \mathrm{~mm}(600 \times 600 \mathrm{DPI})$ 